
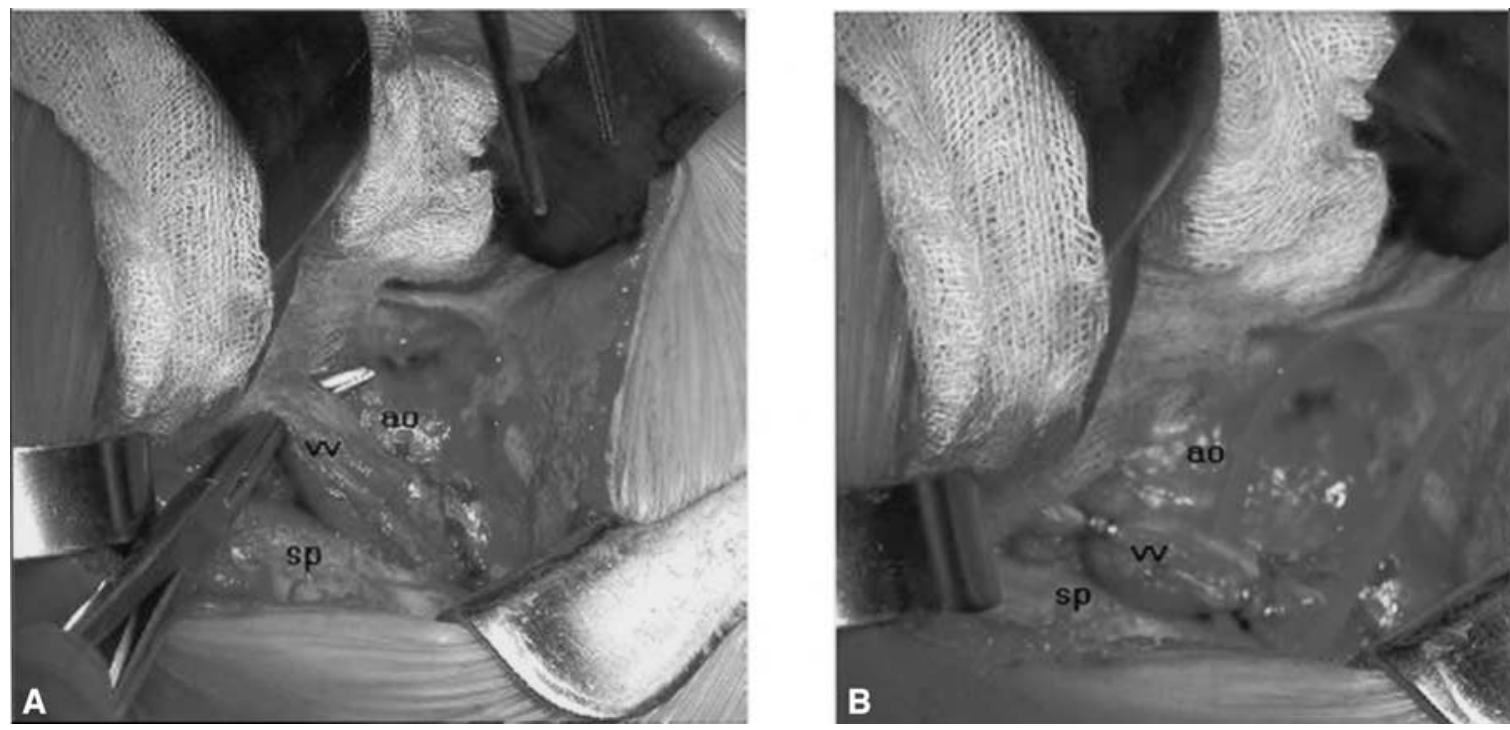

Figure 2. A, Operative view showing wide open VV parallel to aorta (ao) and spine (sp). B, VV is seen to be ligated with double clips.

6. Appelbaum A, Kirklin JW, Pacifico AD, Bargeron LM Jr. The surgical treatment of total anomalous pulmonary venous connection. Isr J Med Sci. 1975;11:89-96.

7. Mathew R, Thilenius OG, Replogle RL, Arcilla RA. Cardiac function in total anomalous pulmonary venous return before and after surgery.
Circulation. 1977;55:361-70

8. Gaynor JW, Collins MH, Rychick J, Gaugan JP, Spray TL. Long term outcome of infants with single ventricle and total anomalous pulmonary venous connection. J Thorac Cardiovasc Surg. 1999; 117:506-13.

\title{
Mitral annular and left ventricular outflow tract enlargement with autologous tissue: Extended application of the Ross-Konno procedure
}

\author{
José M. Caffarena, MD, PhD, ${ }^{a, b}$ Miguel Rovirosa, MD, ${ }^{b}$ and Jose M. Gòmez-Ullate, MD, ${ }^{a}$ Barcelona, Spain
}

$\mathrm{T}$ unnel-type subaortic stenosis with aortic valve involvement combined with mitral stenosis and annular hypoplasia, frequently seen with Shone anomaly or related conditions, may have a severe presentation in infancy, with aortic valvulotomy and mitral valve replacement being nec-

From the Pediatric Cardiac Surgery Department, Children's Hospital La $\mathrm{Fe},{ }^{\mathrm{a}}$ Valencia, and Children's Hospital Sant Joan de Deu, ${ }^{\mathrm{b}}$ Barcelona, Spain.

Received for publication July 12, 2002; accepted for publication July 18, 2002.

Address for reprints: José M. Caffarena, MD, PhD, Pediatric Cardiac Surgery Department, Hospital Infantil La Fe, C/ Avda de Campanar s/n, 46009 Valencia, Spain (E-mail: josecaffarena@telefonica.net).

J Thorac Cardiovasc Surg 2003;125:423-5

Copyright $\odot 2003$ by The American Association for Thoracic Surgery

$0022-5223 / 2003 \$ 30.00+0$

doi: $10.1067 / \mathrm{mtc} .2003 .202$ essary at an early age. ${ }^{1}$ These patients subsequently may have severe gradients across the mitral prosthesis because of body growth, along with frequent complex aortic obstructions that are aggravated by the protrusion of the mitral prosthesis into the left ventricular outflow tract.

Faced with the seeming inevitability of performing a double mitral-aortic valve replacement, we developed an alternative technique that enlarges the mitral annulus, allowing the accommodation of a prosthesis of a greater size and at the same time resolving the complex aortic obstruction. The objective is to minimize the use of prosthetic material and to use autologous tissue in these growing children.

\section{Method}

We use deep hypothermic cardiopulmonary bypass. After aortic crossclamping, blood cardioplegic solution is administered through the aortic root. The retrograde route is used for dose maintenance. The aorta is sectioned along the commissural plane, and the aortic valve is resected, with extraction of coronary arteries 


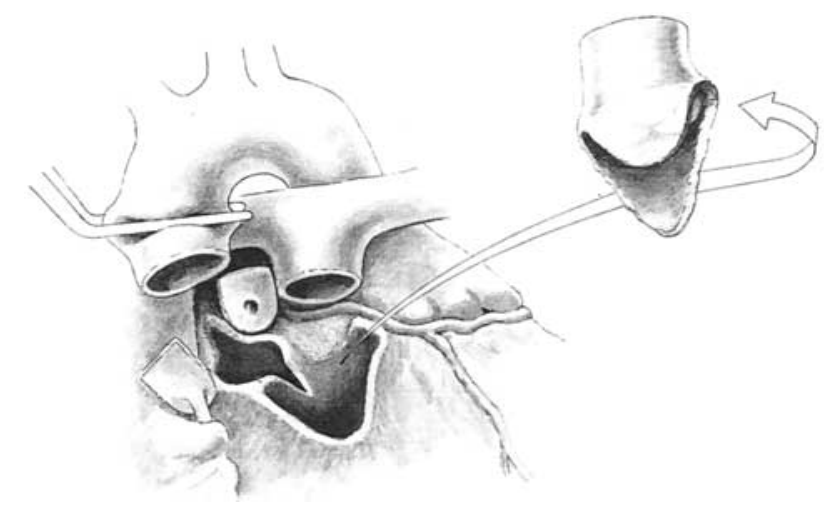

Figure 1. Extended aortic root enlargement over roof of left atrium after resection of native or prosthetic mitral valve. Excision of autograft with double muscular flap.

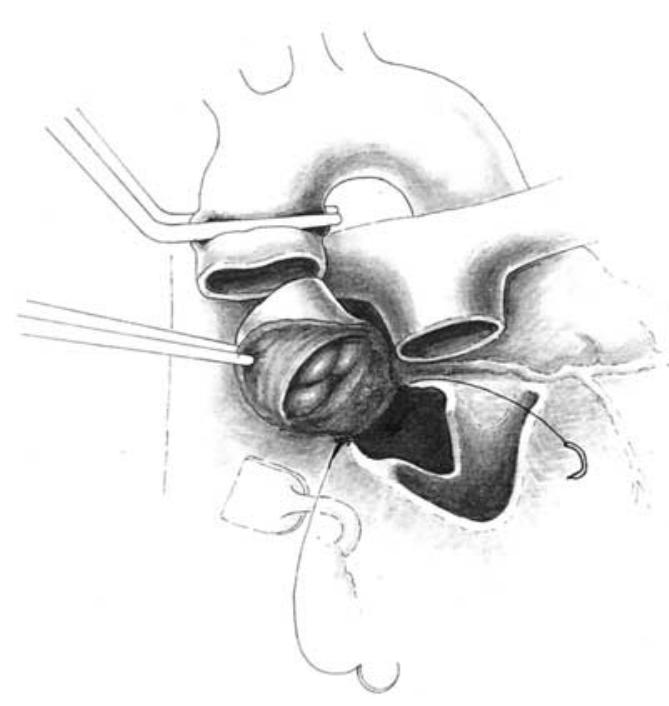

Figure 2. Mitral annular and aortic left ventricular outflow tract enlargement with pulmonary autograft.

and a generous circumference of aortic wall. The free wall of the right atrium is opened and extended over the base of the right atrial appendage toward the interatrial septum and roof of the left atrium.

The interatrial septum is cut longitudinally, and the mitral valve, whether native or prosthetic, is removed. On the remnant of the aortic annulus an incision is made on the noncoronary-left coronary commissure, connecting it with the incision on the roof of the left atrium. The pulmonary autograft is obtained with a double muscular flap, anterior from the free wall and posterior from the septum of the right ventricular infundibulum up to the level permitted by the conal septum (Figure 1). The intercoronary commissure is then opened toward the interventricular septal muscle up to the subaortic obstruction level. The autograft can now be implanted to the base of the enlarged aortic root. The autograft is sutured to the aortic root with the posterior flap for the ventriculoseptoplasty and the anterior muscle flap to enlarge the mitral annulus, with the suture continued along the borders of the incised

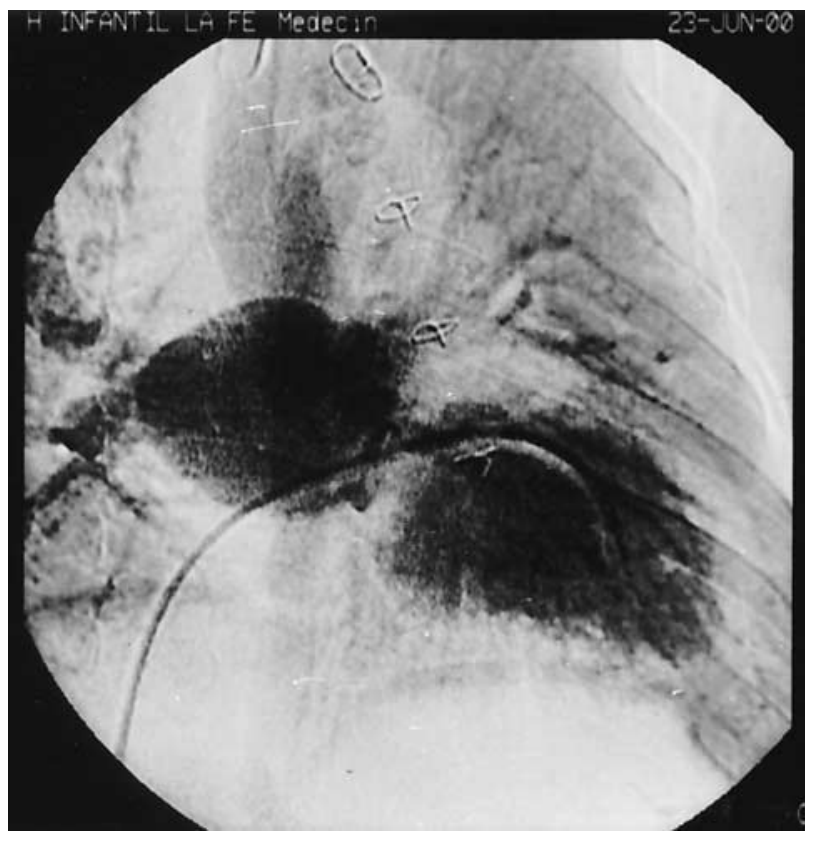

Figure 3. Angiogram showing stenosis of mitral prosthesis with hypoplasia of mitral annulus.

roof of the left atrium (Figure 2). The new mitral prosthesis is sutured to the muscle of the autograft and to the rest of the mitral annulus. The coronary arteries are then reimplanted in the autograft, and it is subsequently anastomosed to the distal aorta. The procedure is concluded with a cryopreserved pulmonary homograft to reestablish ventriculopulmonary continuity.

We have applied this procedure in 2 boys 6 and 8 years old who had severe subaortic tunnel stenosis associated with double mitralaortic valve involvement. At an early age both had undergone coartectomy and open aortic valvulotomy. One of them had undergone mitral valve replacement with a $16-\mathrm{mm}$ mechanical prosthesis, which actually participated in the subaortic obstruction (Figures 3 and 4). With the technique described here, we replaced the native $(15 \mathrm{~mm})$ and prosthetic $(16 \mathrm{~mm})$ mitral valves with larger mechanical prostheses (19 and $21 \mathrm{~mm}$, respectively), creating a naturally reconstructed left ventricular outflow tract without obstruction. An echocardiographic check indicated the absence of significant aortic insufficiency, absence of outflow gradients, and preservation of left ventricular function. Six months after the operation, both patients have normal lifestyles, free of symptoms. One has a definitive pacemaker.

\section{Discussion}

Currently the extended replacement of the aortic root with a pulmonary autograft, the Ross-Konno procedure, is the technique of choice in complex aortic obstructions. ${ }^{2}$ However, there have been few solutions described for simultaneous annular enlargement and mitral valve replacement in these patients. The mitral prosthesis in supra-annular position ${ }^{3}$ and the Konno aortoventriculoplasy with mitral valve replacement, ${ }^{4}$ the techniques most frequently used, are both associated with elevated mortality. Jonas and associates $^{5}$ in 1998 described a new technique of mitral 


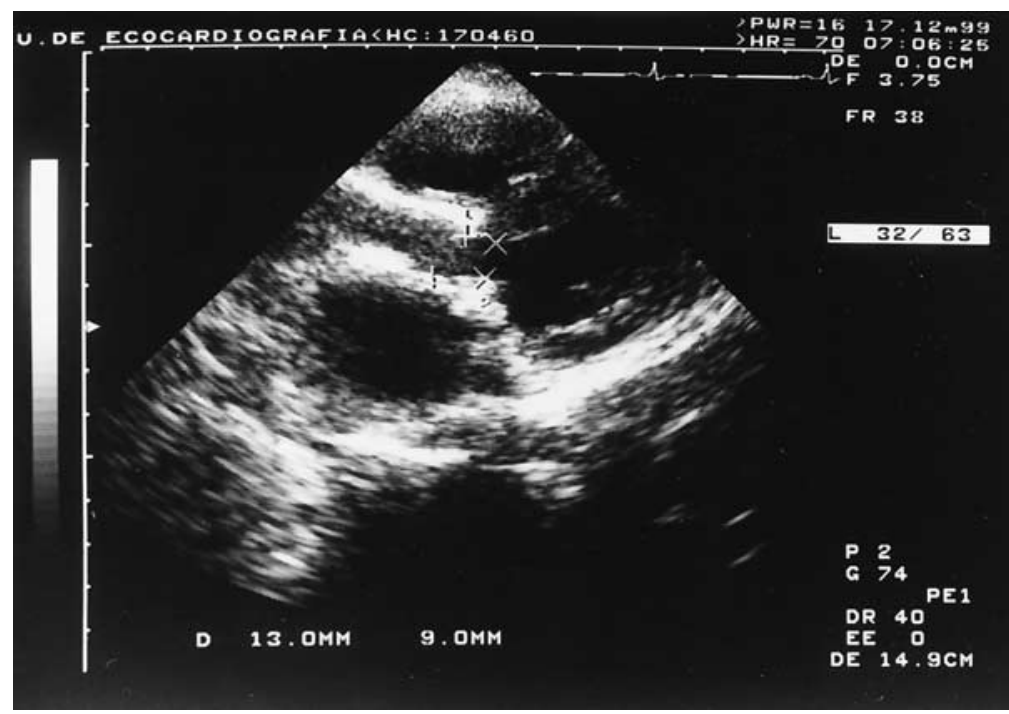

Figure 4. Echocardiogram showing multilevel obstruction in left ventricular outflow tract, with area of maximum narrowing in relation to subaortic protrusion of stenosed mitral prosthesis.

annular and left ventricular outflow tract enlargement that but preserved the aortic valve.

The technique that we describe here is original and has a clear indication for patients with complex subaortic obstruction who also require mitral-aortic double-valve replacement. The use of this technique has allowed us to implant prostheses 4 to $5 \mathrm{~mm}$ larger than the mean size of the native mitral annulus, avoiding protrusion of the prosthesis into the left ventricular outflow tract, which is naturally reconstructed with the extended pulmonary autograft.

The two major complications in relation to the technique described are bleeding and complete block of cardiac conduction. Bleeding may be reduced by strengthening the suture proximal to the autograft with separate stitches supporting polytetrafluoroethylene patches and by reinforcing the posterior muscle of the autograft with a limited band of autologous pericardium. The unclamping of the aorta before placement of the pulmonary homograft allows us to locate and control any hemorrhage with greater ease.

The high incidence of complete block in these patients is related to the ventriculoseptoplasty and the proximal suture of the autograft. To avoid this complication, we must orient the ventriculoseptoplasty from the intercoronary commissure distally to the left, confining it to the severity of the subaortic obstruction.
The initial results in these 2 cases encourage us to propose this technique as an alternative of choice for mitral-aortic double-valve replacement in this difficult group of patients.

\section{References}

1. Shone JD, Sellers RD, Anderson RC, Adams PA, Lillehei CW, Edwards JE. The developmental complex of "parachute mitral valve," supravalvular ring of left atrium, subaortic stenosis and coarctation of the aorta. Am J Cardiol. 1963;11:714-25.

2. Starnes VA, Luciani GB, Wells WJ, Allen RB, Lewis AB. Aortic root replacement with the pulmonary autograft in children with complex left heart obstruction. Ann Thorac Surg. 1996;62:442-8.

3. Adatia I, Moore PM, Jonas RA, Colan SD, Lock JE, Keane JF. Clinical course and hemodynamic observations after supraannular mitral valve replacement in infants and children. J Am Coll Cardiol. 1997;29:1089-94.

4. Brauner RA, Laks H, Drinkwater DC, Schooll F, McCaffery S. Multiple left heart obstructions (Shone's anomaly) with mitral valve involvement: long-term surgical outcome. Ann Thorac Surg. 1997;64: 721-9.

5. Jonas RA, Keane JF, Lock JE. Aortic valve preserving procedure for enlargement of the left ventricular outflow tract and mitral anulus. J Thorac Cardiovasc Surg. 1998;115:1219-22. 